\title{
ÁAirman
}

Jurnal Teknik dan Keselamatan Transportasi

\section{Rancangan Alat Pelepas Pin Piston pada Motor Piston Continental IO-470 dan Lycoming O-360 dengan Menggunakan Pompa Hidrolik di Prodi Teknik Pesawat Udara STPI}

\section{Piston Pin Release Equipment Design on IO-470 Continental Motor and Lycoming O-360 Using Hydraulic Pump in STPI Aircraft Engineering Technique}

\author{
Erlana Ichsan Haryanto ${ }^{1}$, Saddam Rabati ${ }^{2}$, Muawal Al-Asyari ${ }^{3}$ \\ Politeknik Penerbangan Indonesia Curug \\ Politeknik Penerbangan Makassar
}

erlanadgca@gmail.com, saddamrabati@gmail.com, arieliverpudlian12@gmail.com

\begin{abstract}
ABSTRAK
Faktor penunjang tercapainya tujuan tersebut praktek di bengkel piston engine, yang memberi pengalaman dalam perawatan pada piston engine seperti Teledyne Continental IO-470 dan Avco Lycoming O-360. Beraneka ragam alat yang ada saat ini, baik dilihat dari kegunaan maupun fungsinya, namun tidak semua komponen dapat dipasang dan dilepas dengan menggunakan alat, tanpa alat khusus. Pada perawatan khususnya pesawat udara, yaitu bertujuan untuk mempertahankan dan mengembalikan komponen untuk beroperasi dengan aman, contohnya inspeksi 2000 jam dimana pemeriksaan seperti mesin, baling-baling pendorong, roda pendaratan sebagainya. Salah satunya pada pemeriksaan mesin dilakukan pelepasan pin piston sesuai dengan prosedur di maintenance manual, dalam proses pelaksanaannya di bengkel piston engine masih menggunakan mallet dan kayu untuk pelepasan, dengan gaya yang dikeluarkan dari mallet jika terjadi kesulitan pada pelepasan maka dapat melukai permukaan dengan adannya hentakan dan kemelesetan, adapun beberapa faktor internal dari manusia itu sendiri seperti stress dan fatigue. Dari hasil pengamatan gaya yang dihasilkan mallet dengan rata-rata jarak pada objek 0,3m waktu yang dibutuhkan $0,11 \mathrm{~s}$ maka pergeseran pin 0,009m sehingga gaya yang dikeluarkan pada saat memalu 4,95N dan gaya yang dibutuhkan 14,3 pukulan untuk melepas pin piston, sedangkan untuk melepas pin piston dengan enam silinder total yang dikeluarkan 425,31N. Oleh karena itu untuk meningkatkan keamanan dalam perawatan maka penulis merancang alat pelepas pin piston dengan menggunakan pompa hidrolik, dengan total perancangan gaya yang dikeluarkan 425,31N pada aktuator, dengan menggunakan prinsip Pascal sehingga gaya untuk engkol tangan manual 42,17N. Dan alat ini juga dapat menggunakan motor AC untuk memompa fluida dengan daya 500watt dan putaran 2500 rpm.
\end{abstract}

Kata kunci: pin piston; piston; motor hidrolik

\section{ABSTRACT}

Supporting factors for the achievement of these objectives in the piston engine workshop, which provides experience in maintenance of piston engines such as the Teledyne Continental IO-470 and Avco Lycoming O-360. A wide variety of tools currently available, both in terms of use and function, but not all components can be installed and removed using tools, without special tools. In aircraft specific maintenance, that is to repair and repair components for safe repairs, for example a 2000-hour 
inspection where checks such as engines, propellers, landing gear etc. One of them is when checking the engine which is done by removing the piston pin in accordance with the procedures in the maintenance manual, in the process of implementing it in the engine workshop the piston still uses a hammer and wood for release, with the force released from the hammer slip, as for some internal factors of the human itself such as stress and fatigue. From the observations of the force produced by the hammer with an average distance of the object at $0.3 \mathrm{~m}$, the time required is 0.11 seconds, then the pin changes $0.009 \mathrm{~m}$, the new force issued when hammering $4.95 \mathrm{~N}$ and the force required 14.3 times to open piston pin, while to release the piston pin with six cylinders issued a total of $425.31 N$. Therefore, to improve safety in treatment, the authors used a piston pin release tool using a hydraulic pump, with a total design force of $425.31 \mathrm{~N}$ issued on the actuator, using the Pascal principle so that the force for manual hand crank was $42.17 \mathrm{~N}$. And this tool can also use an AC motor to pump fluid with 500watt power and 2500rpm rotation.

Keywords: piston pin; piston; hydraulic motor

\section{PENDAHULUAN}

Dunia penerbangan telah mengalami kemajuan yang sangat pesat. Hal ini tentu saja tidak lepas dari kemajuan teknologi yang semakin berkembang terus dari waktu ke waktu. Kemajuan teknologi dibidang penerbangan tentunya harus diikuti dengan ketersediaan sarana dan prasarana penunjang (Atmia \& Aswar, 2018) serta meningkatnya kemampuan manusia yang menanganinya dengan dilengkapi peralatan dan perlengkapan untuk membantu proses perawatan. Perawatan (maintenance) untuk berbagai sistem pada pesawat udara mutlak diperlukan untuk menjaga kondisi pesawat agar selalu siap dan aman pada saat digunakan. Perawatan yang dibutuhkan untuk memastikan kelaikan udara pesawat terbang, termasuk dari perbaikan, inspeksi, penggantian, dan modifikasi. Setiap orang yang melakukan perawatan, modifikasi, serta pencegahan harus sesuai prosedur dengan standarisasi perintah yang telah ditentukan dalam manual dari perusahaan produsen, untuk kelaikan udara yang telah disetujui oleh Direktorat Jendral Perhubungan Udara. Perawatan berkala dilakukan pada semua pesawat setelah jumlah waktu tertentu dalam penggunaannya.

Perwujudan dari dunia penerbangan berawal di program studi pendidikan Teknik Pesawat Udara tepatnya di Sekolah Tinggi Penerbangan Indonesia yang mendidik dan menghasilkan lulusan yang tangguh bagi kepentingan subsektor perhubungan udara khusus di perawatan pesawat udara dalam keserasian perpaduan ilmu keterampilan, keahlian dalam menunjang keselamatan penerbangan dan nantinya mempunyai kemampuan mengenali, mengamati serta memiliki keahlian yang diperlukan untuk melakukan perawatan di bidang teknik pesawat udara.

Faktor penunjang tercapainya tujuan tersebut adalah dengan adanya praktek di bengkel piston engine, akan memberikan pengalaman dalam perawatan piston engine seperti motor piston Teledyne Continental IO-470 dan Avco Lycoming O-360. Dari beberapa pelaksanaanya, beraneka ragam alat yang ada saat ini, baik dilihat dari kegunaan maupun fungsinya, namun ada beberapa komponen yang tidak dapat dipasang dan dilepas dengan menggunakan alat, tanpa alat khusus. Dalam proses perawatan pesawat udara, salah satunya pelepasan pin piston sesuai dengan maintenace manual, di bengkel piston engine masih menggunakan mallet jika terdapat kesulitan dalam proses pelepasan maka gaya yang dikeluarkan dari mallet tersebut dapat terjadi hentakan yang dapat melukai permukaan pin piston, dan juga gaya yang dikeluarkan dari mallet tersebut dapat menyebabkan kemelesetan dan ketidak konstanan. Hal ini dikarenakan ada beberapa faktor internal dari manusia itu sendiri, faktor-faktor tersebut antara lain seperti: fatigue, stress ataupun lapses akibat dari external environment. Sehingga belum adanya alat khusus dengan ketepatan gaya dorong dan tenaga yang tinggi, dengan menggunakan pompa hidrolik sebagai perancangan untuk melepaskan pin piston.

Oleh karena itu untuk meningkatkan keamanan dalam perawatan maka penulis merancang alat khusus yang dapat membantu melepas piston pin dengan judul "RANCANGAN ALAT PELEPAS PIN PISTON CONTINENTAL IO-470 DAN LYCOMING O-360 DENGAN 


\section{MENGGUNAKAN POMPA HIDROLIK DI PRODI TEKNIK PESAWAT UDARA STPI".}

Berdasarkan latar belakang yang telah ditulis diatas maka dapat diidentifikasikan beberapa masalah yang muncul sebagai berikut :

a. Bagaimana ketepatan dan gaya dorong yang dikeluarkan oleh alat pelepas pin piston terhadap proses pembukaan?

b. Bagaimana penerapan teknologi dibidang pendidikan dengan menggunakan pompa hidrolik untuk melepas pin piston?

c. Bagaimana pengaruh daya motor terhadap kecepatan aliran fluida untuk mendorong sebuah aktuator?

d. Bagaimana merancang alat pelepas pin piston untuk motor Teledyne Continental IO-470 dan Avco Lycoming O-360 menggunakan pompa hidrolik?

Dari pembahasan diatas dan identifikasi masalah maka penulis merumuskan beberapa masalah sebagai berikut:

a. Bagaimana merancang mekanisme pelepas pin piston dengan menggunakan pompa hidrolik motor AC?

b. Bagaimana merancang suatu mekanisme roda gigi untuk menghasilkan putaran yang diinginkan?

c. Bagaimana menentukan komponen alat yang digunakan untuk pelepasan pin piston?

d. Bagaimana menentukan kriteria uji coba terhadap rancangan serta kriteria uji?

Tujuan yang ingin dicapai dari rancangan alat pelepas piston pin ini adalah sebagai berikut :

a. Memberikan suatu tambahan alat di bengkel piston engine untuk proses perawatan.

b. Meningkatkan keamanan pada saat proses perawatan pesawat udara, dengan memperhatikan tenaga yang konstan yang dikeluarkan pada motor AC.

c. Sebagai bahan pertimbangan untuk penelitian selanjutnya dalam merancang agar menjadi lebih baik lagi.

\section{a. Pesawat Piston Engine}

Pesawat piston engine merupakan komponen dari sistem tenaga pendorong untuk pesawat yang menghasilkan daya mekanis. Pesawat yang ekonomis untuk penerbangan jarak dekat yang dengan kapasitas sekitar 3 sampai 8 penumpang, dan biasanya digunakan untuk pribadi dan latihan. Salah satunya di Sekolah Tinggi Penerbangan Indonesia menggunakan pesawat mesin piston Teledyne Continental IO-470 untuk pesawat Beechcraft Barron dan Avco Lycoming $O$-360 untuk pesawat Socata Tobago 10.

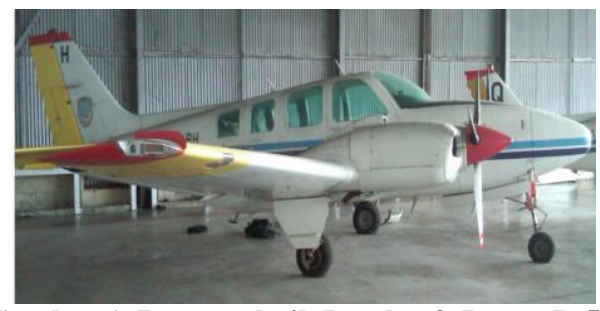

Gambar 1. Pesawat latih Beechraft Baron B-58

Pesawat Beechcraft Baron (lihat Gambar 1) termasuk tipe light aircraft, bermesin piston ganda yang mempunyai berat kotor 5400-5500lb (2450-2500 kg), dan menggunakan mesin Teledyne Continental IO-470 (lihat Gambar 2), memiliki kecepatan sampai $200 \mathrm{knot}(370 \mathrm{~km} / \mathrm{jam})$ pada $8000 \mathrm{knot} \mathrm{ft}$ $(2400 \mathrm{~m})$ dan $220 \mathrm{knot}(410 \mathrm{~km} / \mathrm{jam})$ pada $20000 \mathrm{kaki}(6100 \mathrm{~m})$, dan dikapasitas tangki bahan bakar 190galon AS (719L).

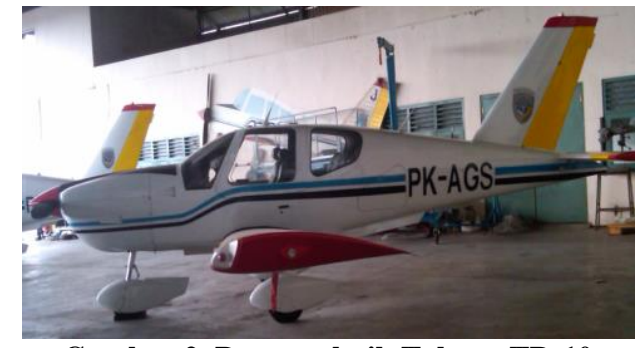

Gambar 2. Pesawat latih Tobago TB-10

Socata Tobago 10 (lihat Gambar 3) termasuk jenis tipe light aircraft dengan motor piston tunggal di produksi oleh Socata. Tipe pesawat ini memiliki variable pitch baling-baling, dan seri $T B$ ini banyak digunakan untuk pelatihan. Pesawat ini memiliki kapasitas 4 kursi dengan kecepatan meluncur $235 \mathrm{~km} / \mathrm{jam}$ (127knot), jarak $985 \mathrm{~km}$ (634mil), ketinggian $3.960 \mathrm{~m}$ (13.000ft). Panjang pesawat $7,75 \mathrm{~m}$ (25ft 5.1in), lebar sayap 9,89m (32ft 5,2in) dan tinggi 3,02m ( $9 f t$ 10,9in). Pesawat jenis ini menggunakan motor piston Lycoming O-360 (lihat Gambar 4), dengan menggunakan empat-silinder yang horisontal bersebrangan, terdapat karburator yang berfungsi untuk mencampur udara dan bahan bakar untuk proses perbakaran secara 
internal, proses pendinginan menggunakan udara, yang menghasilkan 180hp (134kW).

\section{b. Teori Komponen Motor Piston}

Motor piston pada bagian ini merupakan komponen-komponen yang berhubungan dengan pelepasan pin piston, antara lain:

1) Teori Motor Piston

Motor piston merupakan mesin yang merubah energi panas dari bahan bakar yang terbakar menjadi gerakan maju mundur dari piston, yang kemudian diubah menjadi gerakan berputar oleh batang penyambung (conneting rods) dan poros engkol (crankshaft). Gerakan berputar ini yang digunakan untuk menggerakan baling-baling sebagai sumber daya dorong bagi pesawat terbang. Dalam proses kerjanya motor piston didukung oleh beberapa sistem yang saling mempengaruhi dalam memberikan kerja motor piston yang optimal.

2) Piston

Piston merupakan bagian dari motor piston yang bergerak maju mundur maupun naik turun yang disebabkan oleh pembakaran yang terjadi dalam silinder, untuk mengirimkan tenaga dari pembakaran akibat pengembangan gas dalam silinder titik mati bawah pada poros engkol. Pada saat piston bergerak kebawah (kearah poros engkol) dalam silinder, terjadi gerakan asupan, dengan menarik campuran bahan bakar udara. Pada saat bergerak keatas (ke arah kepala silinder), terjadi posisi kompresi kemudian diberikan pengapian yang membawa campuran udara dan bahan bakar, selanjutnya titik mati bawah terjadi pengembangan gas menyebabkan piston untuk bergerak menuju poros engkol. Dan selanjutnya gerakan (ke arah kepala), hal ini membuat tenaga dengan gas pembakaran keluar dari ruang pembakaran. Piston terbuat dari paduan aluminum tempa dan terdapat beberapa bagian: kepala piston (piston head), tepi piston (piston skirt), dan bagian bawah piston kontak dengan minyak pelumas.

3) Cincin Piston (piston ring)

Cincin piston berfungsi sebagai paking (gasket) yang menjaga tekanan dalam ruang bakar (combustion chamber) dan untuk mencegah oli masuk ke dalam ruang bakar serta sebagai penyalur panas dari piston ke dinding silinder (cylinder wall). Terbuat dari besi cetak kelabu berkualitas tinggi (highgrade gray cast iron).
Cincin piston diklasifikasikan menjadi dua fungsi:

1. Cincin tekanan (compression rings) berfungsi untuk mencegah gas masuk kedalam piston selama mesin beroperasi.

2. Cincin oli (oil rings) berfungsi mengendalikan kuantitas oli yang diterdapat pada dinding silinder dan mencegah oli ini lewat ke ruang pembakaran.

a) Pasak Piston (pin piston)

Pasak piston (wrist pin) berfungsi untuk menghubungkan piston dan batang penyambung terbuat dari baja.Pin Piston biasanya diklasifikasikan menjadi 3:

1) Statis/kaku (stationary/rigid)

Jenis statis ini tidak bebas untuk bergerak kesegala arah dan dikencangkan dengan sekrup agar aman.

2) Setengah mengapung (semifloating)

Pin piston semifloating aman dengan pegangan penjepit pada ujung batang penghubung dan lubang setengah pin itu sendiri.

3) Mengapung (full-floating)

Tipe full-floating bergerak bebas pada batang penghubung dan banyak digunakan pada motor piston pesawat.

\section{c. Teori Hidrolik}

Sistem hidrolik merupakan teknologi yang memanfaatkan zat cair yang biasanya menggunakan oli untuk melakukan suatu gerakan. Sistem ini bekerja berdasarkan prinsip jika suatu zat cair diberi tekanan, maka tekanan itu akan merambat kesegala arah dan dapat melewati dalam berbagai ukuran dan bentuk, sehingga fluida dapat mentransfer tenaga dan gaya, sifat fluida cair yang tidak mempunyai bentuk tetap tetapi selalu menyesuaikan bentuk yang ditempatinya.

1) Cairan Hidrolik

Cairan hidrolik fungsinya untuk menyalurkan dan mendisribusikan tenaga yang akan digerakan, dengan memiliki kekentalan yang cukup, memiliki indek viskositas yang baik, tahan api, tidak berbusa, tahan dingin, tahan korosi dan tahan haus minimal kompressibility.

1. Sifat Fluida ideal:

a) Harus mampat.

b) Memiliki kekentalan tidak berpengaruh terhadap suhu. 
c) Viskositas rendah terhadap perubahan suhu.

d) Memberi pelumas yang baik.

e) Tidak menimbulkan bahaya kesehatan yang signifikan pada operator.

f) Flash point diatas $100^{\circ} \mathrm{C}$, dan tidak mudah terbakar.

g) Tidak berbusa.

h) Kimia yang stabil dalam proses operasi.

i) Tidak membahayakan atau merugikan dari bahan yang digunakan dalam sistem pipa dan komponen.

j) Penyimpanan yang baik

2. Syarat cairan Hidrolik :

a) Hambatan aliran (viscosity)

Cairan hidrolik harus tidak terlalu kental dan tidak cair sebagai habatan aliran dalam, viskositas yang berlebihan akan menambah beban, dan jika kurang dapat menyebabkan kehausan.

b) Stabilitas kimia (chemical stability)

Kemampuan cairan hidrolik untuk menahan oksidasi dan gesekan-gesekan yang terus menerus dalam jangka waktu yang lama, jadi cairan hidrolik harus tahan terhadap panas, gesekan dan oksidasi, tidak boleh berubah warna.

c) Titik uap (flash point)

Suatu temperatur dengan cairan mulai menguap dan mudah terbakar jika terkena percikan api, oleh karena itu cairan hidrolik harus memiliki nilai titik uap yang tinggi.

d) Titik api (fire point)

Suatu temperatur dengan cairan mulai menguap dan mudah terbakar terus menerus jika terkena percikan api, oleh karena itu cairan hidrolik harus memiliki nilai titik api yang tinggi.

3. Tipe cairan Hidrolik

Untuk menjamin agar sistem hidrolik dapat bekerja dengan baik serta untuk menghindari kerusakan pada komponenkomponen non metal, maka perlu digunakan cairan hidrolik yang tepat.

Ada tiga macam tipe cairan hidrolik yang digunakan pada system hidrolik :

a) Vegetable base hydraulic fluid (MIL-H7644)

Memiliki komposisi Castrol oil dan Alkohol, diberi warna biru untuk identifikasi, seal dari bahan karet alami dan sistem dapat dibersihkan dengan alkohol.

b) Mineral base hydraulic fluid (MIL-H5606)

Memiliki komposisi minyak hasil minyak bumi, dengan karakteristik pelumas yang baik dan aditif untuk menghambat busa dan mencegah pembentukan korosi. diberi warna merah untuk identifikasi, seal dari bahan karet sisntesis / buna-N, dapat dibersihkan dengan naptha, varsol, atau stoddard solvent.

c) Systetic base hydraulic fluid (MIL-H8446)

Memiliki nama lain skydroll-500A komposisi synthetic phosphate ester fluid, diberi warna ungu cerah, seal dari Butyl, Teflon, Silicon Rubber dapat dibersihkan dengan Trichlorethylene, tahan panas dan tahan api (sekitar $65^{\circ} \mathrm{F}$ sampai $225^{\circ} \mathrm{F}$ ).

\section{METODE}

a. Jenis dan Sumber Data

Dalam menyusun perancangan alat pelepas piston pin ini maka metodologi perancangan yang digunakan adalah sebagai berikut :

1) Tinjauan pustaka; mengacu pada referensi data teoritis yang diambil dari buku-buku yang berhubungan dengan perancangan.

2) Metode interview; konsultasi dengan pihak yang terlibat dalam hal ini instruktur dan orang-orang yang berperan dalam praktek piston engine.

3) Metode observasi; mencari data yang berhubungan dengan mekanisme perancangan.

4) Metode ekperimen; percobaan terhadap rancangan yang telah selesai dibuat.

\section{b. Waktu dan lokasi penelitian}

Penelitian dilakukan di Sekolah Tinggi Penerbangan Indonesia. Program Studi Teknologi Pemeliharaan Pesawat Udara (TPPU) yang akan dimulai pada bulan Juli 2018.

\section{HASIL DAN PEMBAHASAN}

Konsep rancangan ini yang akan dibuat menggunakan hidrolik dan motor listrik AC untuk pelepasan pin piston.

Perencanaan Hidrolik dan Motor AC 
1) Perencanaan Silinder

Silinder yang dipakai adalah tipe single action, dengan asumsi beban yang diterima adalah berasal dari pin piston, dengan asumsi beban awal $F_{s 6}=425,31 \mathrm{~N}$.

$$
F_{i}=425,31 \mathrm{~N} \times \frac{0,22481 \mathrm{lb}}{N}=95,61 \mathrm{lb}
$$

direncanakan tekanan silinder aktuator ( $\mathrm{P}_{\mathrm{A}}$ ) adalah 6 bar

$$
P_{A}=6 b a r \times \frac{14,696 p s i}{b a r}=88,18 p s i
$$

Beban total $\left(F_{i}\right)$ yang terjadi adalah beban awal ditambah gaya gaya gesek $\left(F_{f}\right)$ kinetik besi dengan besi yang mempunyai koefisien gesek 0,10 .

$$
\begin{aligned}
F_{f} & =\mu \times F_{i} \\
& =0,1 \times 95,61 \\
& =9,56 l b
\end{aligned}
$$

Maka beban total adalah

$$
\begin{aligned}
F_{A} & =F_{i}+F_{f} \\
& =95,61 \mathrm{lb}+9,56 \mathrm{lb} \\
& =105,175 \mathrm{lb}
\end{aligned}
$$

Bahan Mild steel dengan properties

Kekuatan tarik $=78300$ psi

- Modulus elastisitas $(E)=29.000 .000 p s i$

- Merancang diameter dan tebal silinder penggerak (aktuator)

Untuk mengetahui tekanan dalam aktuator silinder, dengan rumus hukum Pascal.

$$
\begin{gathered}
F_{A}=P_{A} \times A_{A} \\
A_{A}=\frac{F_{A}}{P_{A}}
\end{gathered}
$$

Sedangkan untuk perencanaan besarnya diameter silinder hidrolik, maka tekanan dan gaya yang dialami silinder penggerak dengan luasan penampang berbentuk lingkaran, menggunakan rumus.

$$
\begin{aligned}
\frac{\pi D_{A}^{2}}{4} & =\frac{\boldsymbol{F}_{\boldsymbol{A}}}{\boldsymbol{P}_{\boldsymbol{A}}} \\
\boldsymbol{D}_{\boldsymbol{A}} & =\sqrt{\frac{4 \boldsymbol{F}_{\boldsymbol{A}}}{\pi \boldsymbol{P}_{A}}} \\
& =\sqrt{\frac{4 \times 105,175}{\pi \times 88,176}} \\
& =1,233 \mathrm{inch} \\
& =1,233 \mathrm{inch} \times \frac{25,4 \mathrm{~mm}}{\text { inch }}=31,31 \mathrm{~mm}
\end{aligned}
$$

Tebal dinding silinder yang diperlukan, dengan memakai bahan mild steel, yang memiliki kekuatan tarik sebesar 78300psi, dengan tekanan yang diberikan sebesar 88,176psi adalah:

$$
\begin{aligned}
t & =\frac{P_{A} \times D_{A}}{2 \sigma_{u}} \\
& =\frac{88,176 \times 1,233}{2(78300)} \\
& =0,001 \text { inch } \\
& =0,001 \text { inch } \times \frac{25,4 \mathrm{~mm}}{\text { inch }}=0,018 \mathrm{~mm}
\end{aligned}
$$

2) Perencanaan Diameter Aktuator

Panjang batang piston direncanakan $100 \mathrm{~mm},\left(100 \mathrm{~mm} \times \frac{i n c h}{25,4 \mathrm{~mm}}=3,94 i n c h\right)$,

sedangkan diameter batang piston dihitung dengan mempertimbangkan faktor buckling sehinga diameter yang tepat tentunya akan menghindari terjadinya fenomena buckling dimana gaya buckling yang dapat timbul dari suatu proses pembebanan.

$$
F_{B}=\frac{\pi^{2} \times E \times 0,0491 D^{4}}{n \times L_{K}^{2}}
$$

Syarat agar tidak terjadi buckling, maka gaya buckling lebih besar dari gaya trust aktuator atau beban total $\left(F_{B}\right)$, diambil gaya buckling sebesar $150 \mathrm{lb}$. Panjang batang piston direncanakan 3,94inch, sehingga dari konstruksi diperoleh nilai $L_{k}=2 L=2 \times 3,94$ inch $=7,874$ inch 1 .

$$
\begin{aligned}
D_{P A} & =\sqrt[4]{\frac{F_{B} \times 3,5 \times L_{k}^{2}}{\pi^{2} \times E \times 0,0491}} \\
& =\sqrt[4]{\frac{150 \times 3,5 \times 7,87^{2}}{\pi^{2} \times 29000000 \times 0,049}} \\
& =0,0023 \text { inch } \\
& =0,023 \text { inch } \times \frac{\mathrm{mm}}{25,4 \text { inch }}=0,218 \mathrm{~mm}
\end{aligned}
$$

Karena diameter batang piston lebih kecil dari diameter silinder aktuator maka jika diameter batang piston $\left(D_{P A}\right)$ direncanakan 
sama dengan diameter aktuator maka batang piston aman dari gaya buckling.

3) Perencanaan Pompa

Skema pompa hidrolik yang digunakan dapat dilihat pada gambar berikut ini:

Direncanakan pompa hidrolik yang digunakan sebagai berikut :

- Diameter piston $\left(\mathrm{D}_{\mathrm{pp}}\right)=9,4 \mathrm{~mm}$ $\left(9,4 \mathrm{~mm} \times \frac{\text { inch }}{25,4 \mathrm{~mm}}=0,37\right.$ inch $)$

- Panjang stroke $\left(\mathrm{L}_{\mathrm{pp}}\right)=2 \mathrm{x}$ esentrik $=2 \mathrm{x}$ $12 \mathrm{~mm}=24 \mathrm{~mm}$

$$
\left(24 \mathrm{~mm} \times \frac{\text { inch }}{25,4 \mathrm{~mm}}=0,945 \mathrm{inch}\right)
$$

4) Langkah Pemompaan

Displacemen aktuator per satu kali pemompaan pompa hidrolik dapat dicari dengan asumsi volume fluida yang dipompakan dengan terdistribusi fluida kesemua dengan kata lain tidak ada kebocoran serta faktor kompresibility minyak diabaikan :

$$
V_{P}=V_{D A}
$$

$V_{P}$ (volume pompa hidrolik satu kali pemompaan $)=V_{P P} \times 1$ langkah

$$
\begin{aligned}
V_{P} & =\frac{\left(\frac{\pi \times D_{p p}^{2} \times L_{P P}}{4}\right)}{\text { langkah }} \times 1 \text { langkah } \\
& =\frac{\pi \times(0,433)^{2} \times 0,945}{4} \\
& =0,102 \text { inch }^{3}
\end{aligned}
$$

Maka displacement aktuator $\left(L_{D A}\right)$

$V_{D A}=\frac{\pi \times D_{A}^{2} \times L_{D A}}{4}$

Keterangan :

$V_{D A}=$ Volume displacement aktuator $\left(\right.$ inch $\left.^{3}\right)$

$D_{A}=$ Diameter aktuator (inch)

$\mathrm{L}_{\mathrm{A}}=$ Displacement aktuator (inch)

$$
\begin{aligned}
L_{D A} & =\frac{4 \times V_{D A}}{\pi \times D_{A}^{2}} \\
& =\frac{4 \times 0,139}{\pi \times(1,608)^{2}} \\
& =0,085 \text { inch }
\end{aligned}
$$

5) Perencanaan Gaya Tekan Pompa

Berdasarkan Gambar 33 dan hukum Pascal maka gaya yang dihasilkan untuk pemompaan adalah:

$$
\begin{aligned}
P_{1} & =P_{2} \\
\frac{F_{P}}{A_{P}} & =\frac{F_{A}}{A_{A}} \\
F_{P} & =\frac{F_{A}}{A_{A}} \times A_{P}
\end{aligned}
$$

Direncanakan diameter pemompa $D_{P P}=$ 0,433 inch sedangkan diameter actuator $D_{A}$ $=1,233$ inch sehingga gaya yang dibutuhkan untuk melakukan pemompaan adalah

$$
\begin{aligned}
& F_{P}=\frac{F_{A}}{0,25 \times \pi \times D_{A}^{2}} \times 0,25 \times \pi \times D_{P P}^{2} \\
& =F_{A} \times \frac{D_{P P}^{2}}{D_{A}^{2}} \\
& =105,175 \times \frac{(0,433)^{2}}{(1,233)^{2}} \\
& =9,48 \mathrm{lb} \\
& =9,48 \mathrm{lb} \times \frac{N}{0,22481 \mathrm{lb}} \\
& =42,169 \mathrm{~N}
\end{aligned}
$$

Sehingga diperoleh volume tangki dengan menambah factor koreksi $25 \%$ dari total awal

$$
V_{T}=1,25 \times(0,104+4,7)=6,001 \text { inch }^{3}
$$

6) Pemilihan Fluida 
Tabel 1. Properties dari EnergolHLP-HM 32

\begin{tabular}{cc}
\hline Karakteristik & Nilai \\
\hline Viskositas & \\
$40^{\circ} \mathrm{C}, \mathrm{cSt}$ & 33,3 \\
$100^{\circ} \mathrm{C}, \mathrm{cSt}$ & 5,5 \\
Viskoitas Index & 100 \\
Flash Point, ${ }^{\circ} \mathrm{F}$ & 390 \\
Pour Point, ${ }^{\circ} \mathrm{F}$ & -25 \\
Viskositas kinematis, $\mathrm{mm}^{2} / \mathrm{sec}$ & 14 \\
Gravity, ${ }^{\circ} \mathrm{API}$ & 30,4 \\
\hline
\end{tabular}

Fluida yang digunakan pada hidrolik ini cairan yang sering digunakan yang ada dipasaran. Jenis fluida yang dipakai adalah mineral base fluid dengan merek dagang Energol ${ }^{\circledR}$ HLP-HM 32. Fluida ini memiliki karakteristik fluida dengan sifat pelumasnya sangat baik dan dapat mencegah terjadinya karat.

Dalam sistem hidrolik tidak terlepas dari seal dan saluran hidrolik sendiri. Jenis seal yang dipakai harus menyesuaikan dengan cairan hidrolik yang dipakai, sehingga seal yang sesuai adalah berbahan neoprene atau karet sintetik.

\section{KESIMPULAN}

a. Berdasarkan uji kelengkapan maka untuk rancangan ini dapat dibuat dengan hasil perhitungan dan menyesuaikan produk di pasaran pada pemilihan hidrolik diameter aktuator 0,885inch menyesuiakan dengan diameter pin piston tersebut dan motor AC dengan putaran $2500 \mathrm{rpm}$ dan daya yang digunakan 500watt.

b. Berdasarkan dari uji kelengkapan terhadap komponen maka dilakukan uji fungsi terhadap tiap masing komponen agar dapat bekerja sesuai dengan fungsinya untuk melepas pin piston.

c. Berdasarkan dari pengujian kinerja untuk alat tersebut dapat berfungsi mendorong beban sampai $425 N$, untuk melepas pin piston dan sedangkan gaya yang dikeluarkan kelika memalu $4,95 \mathrm{~N}$.

Hasil dari penelitian ini menyarankan:

a. Diharapkan alat ini dapat digunakan untuk membantu proses kegiatan praktek. b. Untuk perancangan dan penelitian yang akan datang diharapkan disempurnakan kembali dan lebih efisien dan lebih baik lagi.

c. Diharapkan dalam pemakaian alat ini harus sesuai dengan prosedur yang telah ditetapkan

d. Perawatan dan pemeliharaan pada rancangan alat ini diharapkan tidak ada kerusakan struktur akibat pengaruh lingkungan dan sesuai dengan prosedur yang telah ditentukan.

\section{DAFTAR PUSTAKA}

Airframe Handbook. (1972). Federal Aviation Administration, Oklahoma.

Benc Mc Kinley. (1967). Aircraft Maintenance and Repair, USA: Mc Graw Hill Book Company, Northop Institute of Technology.

David Halliday dan Robert Resnick. (1987). Fisika Edisi ke-3 Jilid 1, Erlangga Jakarta.

Federal Aviation Administration. (1972). General Handbook. Oklahoma.

Mannesmann Rexroth AG, Lohr a. Main. (1991). Basic Principles and Components of Fluid Technology.

M Galal Rabie. (2009). Fluid Power Engineering, Mc Graw Hill.

Ravi Donnavar, Andries Barnard. (2005). Practical Hydraulic System, Elsevier Science \&Technology Book Publisher.

RS Khurmi \& J K Gupta. (1995). A Text-Book of Hydraulic, New Delhi: Eurasia Publishing House.

RS Khurmi \& J K Gupta. (1995). Machine Design, New Delhi: Eurasia PublishingHouse.

Suprayitno, Tony. (2004). Peran Daily Check danPreventive Maintenance dalam Program TPM di PT. SPINDA unit 1. Surabaya : Universitas Petra.

Sularso. (2002). Dasar Perencanaan dan Pemilihan Elemen Mesin, Jakarta: Pradnya Paramita. 
Wen Kurniawan, Michael. (2000). Perencanaan Penjadwalan Perawatan Mesin Produksi di PT. Soponyono. Surabaya : Universitas Petra.

Williamsport Pennsylvania. (1974). Overhaul Manual - Avco Lycoming Direct Drive Aircraft Engines.

Young and Freedman. (2002). Fisika Universitas, Erlangga, Jakarta. 